\title{
Article \\ Selenite Substituted Calcium Phosphates: Preparation, Characterization, and Cytotoxic Activity
}

\author{
Antonia Ressler*(D), Maja Antunović, Matija Cvetnić, Marica Ivanković and Hrvoje Ivanković \\ Faculty of Chemical Engineering and Technology, University of Zagreb, Marulićev trg 19, p.p.177, \\ HR-10001 Zagreb, Croatia; maja.antunovic2007@gmail.com (M.A.); mcvetnic@fkit.hr (M.C.); \\ mivank@fkit.hr (M.I.); hivan@fkit.hr (H.I.) \\ * Correspondence: aressler@fkit.hr
}

check for updates

Citation: Ressler, A.; Antunović, M.; Cvetnić, M.; Ivanković, M.; Ivanković, H. Selenite Substituted Calcium Phosphates: Preparation,

Characterization, and Cytotoxic Activity. Materials 2021, 14, 3436. https://doi.org/10.3390/ ma14123436

Academic Editors: Tanja Pušić, Mirela Leskovac and Tihana Dekanić

Received: 24 May 2021

Accepted: 16 June 2021

Published: 21 June 2021

Publisher's Note: MDPI stays neutral with regard to jurisdictional claims in published maps and institutional affiliations.

Copyright: (c) 2021 by the authors. Licensee MDPI, Basel, Switzerland. This article is an open access article distributed under the terms and conditions of the Creative Commons Attribution (CC BY) license (https:// creativecommons.org/licenses/by/ $4.0 /)$.

\begin{abstract}
The aim of this study was to prepare a biomimetic selenium substituted calcium phosphate system for potential application in osteosarcoma therapy. Calcium phosphate (CaP) systems substituted with selenite ions were prepared by the wet precipitation method, using biogenic $\mathrm{CaCO}_{3}$ (derived from cuttlefish bone), $\mathrm{CO}\left(\mathrm{NH}_{2}\right)_{2}-\mathrm{H}_{3} \mathrm{PO}_{4}$, and $\mathrm{Na}_{2} \mathrm{SeO}_{3} \cdot 5 \mathrm{H}_{2} \mathrm{O}$ as reagents. Starting reaction mixtures were prepared based on the formula for selenite-substituted hydroxyapatite, $\mathrm{Ca}_{10}\left(\mathrm{PO}_{4}\right)_{6-x}\left(\mathrm{SeO}_{3}\right)_{x}(\mathrm{OH})_{2}$, with $\mathrm{Ca} /(\mathrm{P}+\mathrm{Se})$ molar ratio of 1.67 and Se/ $(\mathrm{P}+\mathrm{Se})$ molar ratio of: 0 , $0.01,0.05$, and 0.10 , respectively. The prepared $\mathrm{CaP}$ powders were characterized by Fourier transform infrared spectrometry, elemental analysis, scanning electron microscopy, X-ray powder diffraction analysis and Rietveld refinement studies. Phase transformation and ion release were analyzed during 7 days of incubation in simulated body fluid at $37^{\circ} \mathrm{C}$. The metabolic activity of healthy and osteosarcoma cell lines was assessed by cell cytotoxicity and viability test. The as-prepared powders were composed of calcium-deficient carbonated hydroxyapatite (HAp), octacalcium phosphate (OCP), and amorphous calcium phosphate (ACP). Along with the selenite substitution, the presence of $\mathrm{Sr}^{2+}, \mathrm{Na}^{+}$, and $\mathrm{Mg}^{2+}$ was detected as a result of using cuttlefish bone as a precursor for $\mathrm{Ca}^{2+}$ ions. Inductively coupled plasma mass spectrometry analysis showed that the $\mathrm{Se} /(\mathrm{P}+\mathrm{Se})$ molar ratios of selenite substituted powders are lower than the nominal ratios. Heat treated powders were composed of HAp, $\alpha$-tricalcium phosphate $(\alpha$-TCP) and $\beta$-tricalcium phosphate $(\beta$-TCP). Doping CaP structure with selenite ions improves the thermal stability of HAp. The powder with the $\mathrm{Se} /(\mathrm{P}+\mathrm{Se})$ molar ratio of 0.007 showed selective toxicity to cancer cells.
\end{abstract}

Keywords: biomaterials; hydroxyapatite; ionic substitutions; octacalcium phosphate; osteosarcoma; selenite

\section{Introduction}

Until recently, hydroxyapatite $\left(\mathrm{HAp}, \mathrm{Ca}_{10}\left(\mathrm{PO}_{4}\right)_{6}(\mathrm{OH})_{2}\right)$ was considered to be the main inorganic component of bone tissue. However, recent studies and advanced techniques have shown that biological apatite is characterized by a more complex structure [1]. Firstly, amorphous calcium phosphate (ACP) and octacalcium phosphate (OCP) are formed and apatite is precipitated through phase transformation at physiological conditions [2]. Biological apatite is non-stoichiometric carbonated hydroxyapatite with a considerably reduced content of calcium and hydroxyl groups. Its structure is multi-substituted with various ions, primarily magnesium $\left(\mathrm{Mg}^{2+}\right)$, sodium $\left(\mathrm{Na}^{+}\right)$, strontium $\left(\mathrm{Sr}^{2+}\right)$, potassium $\left(\mathrm{K}^{+}\right)$, zinc $\left(\mathrm{Zn}^{2+}\right)$, manganese $\left(\mathrm{Mn}^{2+}\right)$, carbonate $\left(\mathrm{CO}_{3}{ }^{2-}\right)$, and hydrogen phosphate $\left(\mathrm{HPO}_{4}{ }^{2-}\right)$. The trace elements substituted in HAp lattice affect its properties such as the crystal size, crystallinity level, agglomeration tendency, solubility, morphology, lattice parameters, thermal properties, and bioactivity [3,4].

Bone cancer is one of the most prevalent cancers with the lowest long-term survival rate. Osteosarcoma is an immensely malignant bone tumor that happens most often in young children, adolescents, and young adults. The current treatment of osteosarcoma 
includes surgery, radiotherapy, and chemotherapy [5]. The HAp itself has strong apoptosis induction efficacy on many cancer cells [6]. However, to create more functionalized calcium phosphate $(\mathrm{CaP})$ materials, modification studies have attracted attention, especially doping the structure with target ions [7].

Selenium is an essential element for the proper functioning of bone tissue with strong antioxidant properties $[1,6]$. There have been reports on the positive effects of selenium on cardiovascular diseases, cancers, the brain, reproduction, viral infections, and bone tissue [1]. Selenium may play an important role in protection against osteoarthritis, rheumatoid arthritis, or osteoporosis [1]. Selenium deficiencies may delay growth and affect the metabolism of bone tissue [1]. The mechanism of these processes is associated with the function of selenoproteins, of which at least nine are expressed in human fetal osteoblasts. Their expression seems to protect bones from oxidative stress, which is important in the regulation of inflammation and the differentiation of bone cells [1,5]. In recent years, selenium has attracted attention as $\mathrm{CaP}$ substituent as it can induce tumor cell apoptosis [7]. In vitro and in vivo studies obtained by Wang et al. confirmed that Se-substituted HAp has antitumor activity and can induce the apoptosis of human osteosarcoma cells [8]. HAp substituted with selenite ions had pronounced inhibitory effects on the osteosarcoma cell line, while leaving regular fibroblasts intact as reported by Uskoković et al. [9]. However, the cytotoxicity of $\mathrm{SeO}_{3}{ }^{2-}$-substituted HAp relies on its $\mathrm{pH}$-dependent release into the medium and a high concentration of selenium is suggested to induce non-selective cytotoxicity [9]. As reported, a high $\mathrm{SeO}_{3}{ }^{2-}$-content $(3.0 \mathrm{wt} \%)$ induced non-cancerous MC3T3-E1 cell death with abnormal morphological changes as early as $24 \mathrm{~h}$ of treatment and decreased the expression of bone $\gamma$-carboxyglutamate protein 3 (BGLAP3) [9].

Selenium doped HAp is most frequently obtained by wet precipitation methods, using $\mathrm{SeO}_{3}{ }^{2-}$ ions as a source of selenium [6-10]. To the best of our knowledge no study on synthesis and characterization of Se-substituted CaPs, derived from cuttlefish bone, has been reported. The use of natural resources such as cuttlefish bone for preparing CaPs is a promising concept since these resources bring, besides the calcium, many beneficial ions found in human bones. In the present research, Se-substituted CaPs powders (CaP_Se) were synthesized by precipitation method at mild conditions. The effect of Se-substitution on quantitative phase content, lattice parameters, thermal stability, and cell viability of healthy and osteosarcoma cells have been studied. Additionally, an ion release study and a phase transformation after 7 days of incubation in simulated body fluid at $37^{\circ} \mathrm{C}$ were conducted.

\section{Materials and Methods}

\subsection{Synthesis of Selenium Substituted Calcium Phosphates}

As a source of $\mathrm{Ca}^{2+}$ ions, $\mathrm{CaCO}_{3}$ was used, obtained from cuttlefish bone as described in our previous paper [11]. The non-substituted CaP_0Se system was prepared by adding urea phosphate (UPH, $\mathrm{CO}\left(\mathrm{NH}_{2}\right)_{2}-\mathrm{H}_{3} \mathrm{PO}_{4}$, Sigma Aldrich, St. Louis, MO, USA) into dissolved/suspended $\mathrm{CaCO}_{3}$ at $50{ }^{\circ} \mathrm{C}$, while stirring was continued for 4 days followed by overnight aging at room temperature $\left(\mathrm{T}=23.0 \pm 0.2^{\circ} \mathrm{C}\right)$. In order to obtain a Se-substituted $\mathrm{CaP}$ system, sodium selenite pentahydrate $\left(\mathrm{Na}_{2} \mathrm{SeO}_{3} \cdot 5 \mathrm{H}_{2} \mathrm{O}\right.$, Sigma Aldrich, St. Louis, $\mathrm{MO}$, USA) was added before $\mathrm{CaCO}_{3}$ at $30^{\circ} \mathrm{C}$. Four samples with different $\mathrm{Se} /(\mathrm{P}+\mathrm{Se})$ molar ratios $(0,0.01,0.05$, and 0.10$)$ have been prepared and labelled CaP_Se0,CaP_Se1, CaP_Se5, and CaP_Se10, respectively. According to the literature [10], in the selected range of Se/(P + Se) molar ratios, no secondary phases (other than hydroxyapatite) were expected. $\mathrm{The} \mathrm{Ca} /(\mathrm{P}+\mathrm{Se})$ molar ratio was fixed at 1.67. The corresponding amount of the reagents in starting reaction mixtures are listed in Table 1. Supernatant and CaP particles were separated by filtering without washing. Parts of the as-prepared powders were sintered at $1200{ }^{\circ} \mathrm{C}$ for $2 \mathrm{~h}$. Finally, part of obtained as-prepared CaP, CaP_Se0 and CaP_Se5 powders were incubated in simulated body fluid (SBF, reagents were purchased from Sigma Aldrich, St. Louis, MO, USA) for 7 days at $37^{\circ} \mathrm{C}$. Non-substituted CaP powder obtained from synthetic $\mathrm{CaCO}_{3}$ as described in [11] was used as control. 
Table 1. Quantities of reactants and nominal composition of Se-substituted calcium phosphates.

\begin{tabular}{|c|c|c|c|c|}
\hline & $\mathrm{CaCO}_{3}(\mathrm{mmol})$ & UPH (mmol) & $\mathrm{Na}_{2} \mathrm{SeO}_{3} \cdot 5 \mathrm{H}_{2} \mathrm{O}(\mathrm{mmol})$ & Nominal Se/(P + Se $)$ \\
\hline CaP_Se0 & 4.977 & 2.985 & 0.000 & 0.00 \\
\hline CaP_Se1 & 4.977 & 2.955 & 0.030 & 0.01 \\
\hline CaP_Se5 & 4.977 & 2.834 & 0.149 & 0.05 \\
\hline CaP_Se10 & 4.977 & 2.687 & 0.299 & 0.10 \\
\hline
\end{tabular}

\subsection{Characterization of Selenium Substituted Calcium Phosphates}

The final $\mathrm{pH}$ of prepared $\mathrm{CaP}$ suspensions was measured on a Schott CG $842 \mathrm{pH}-$ meter (Schott, Mainz, Germany) using a BlueLine 14 electrode with a precision of 0.01 at room temperature $\left(\mathrm{T}=23.0 \pm 0.2^{\circ} \mathrm{C}\right)$.

The elemental content of prepared $\mathrm{CaP}$ enriched with selenium oxyanion was analyzed by inductively coupled plasma mass spectrometry (ICP-MS), using a PerkinElmer SCIEXT ELANR DRC-e (PerkinElmer, Concord, ON, Canada). The analyses were performed according to the manufacturer's protocol as described in our previous paper [11].

The Fourier transform infrared spectra (FTIR) was carried out using an attenuated total reflectance (ATR) spectrometer for solids with diamond crystal (Bruker Vertex 70, Bruker optics, Ettlingen, Germany) at $20{ }^{\circ} \mathrm{C}$ over the spectral range of $4000-400 \mathrm{~cm}^{-1}$, with 32 scans and $4 \mathrm{~cm}^{-1}$ of resolution.

The powder morphology was analyzed by scanning electron microscopy (SEM, TESCAN Vega3 EasyProbe, Kohoutovice, Czech Republic) at an electron beam energy of $13 \mathrm{keV}$. Dried powders were coated with plasma of gold and palladium for $60 \mathrm{~s}$.

The as-prepared and heat-treated samples mixed with $5 \mathrm{wt} \%$ of polycrystalline silicon (NIST SRN 640e, Sigma Aldrich, St. Louis, MO, USA) were characterized by X-ray diffraction (XRD) analysis using a Shimadzu XRD-6000 diffractometer (Shimadzu, Duisburg, Germany) with $\mathrm{Cu} \mathrm{K} \alpha(1.5406 \AA)$ radiation operated at $40 \mathrm{kV}$ and $30 \mathrm{~mA}$. The diffraction patterns were collected in the $2 \theta$ range $3-60^{\circ}$ for as-prepared and $20-70^{\circ}$ for heat treated samples, with a step size of $0.02^{\circ}$ and exposure of $10 \mathrm{~s}$.

\subsection{Rietveld Refinement Studies}

The obtained collection of X-ray powder diffraction pattern data was used for Rietveld refinement studies performed by means of the software DIFFRAC.SUITE TOPAS V.5.0. (Bruker, Karlsruhe, Germany) with the fundamental parameters approach. Additionally, the Si-standard was used to estimate the instrumental parameters (e.g., $2 \theta$ correction). The structural parameters of HAp, reported by Veselinović et al. [12], OCP by Espanol et al. [13], $\beta$-tricalcium phosphate ( $\beta$-TCP) by Yashima et al. [14], and $\alpha$-tricalcium phosphate $(\alpha$-TCP) by Mathew et al. [15] have been used as the initial values in the refinements. Refined parameters were phase weight percentage, lattice parameters, scale factor, and specimen displacement. The weighted profile $R$-factor $\left(R_{w p}\right)$ and expected $R$ factor $\left(R_{\exp }\right)$ were used to assess the goodness-of-fit of the Rietveld refinement. The results with $R_{w p}<10 \%$ and $\mathrm{R}_{\exp }<3 \%$ were considered to be acceptable.

\subsection{Ion Release Study}

To examine in vitro ion release, as-prepared $\mathrm{CaP}, \mathrm{CaP} \_\mathrm{Se} 0$ and $\mathrm{CaP} \_\mathrm{Se} 5$ powders were incubated in static simulated body fluid (SBF, $\mathrm{pH} 7.4$ ) at $37^{\circ} \mathrm{C}$. The SBF solution was prepared as previously described by Bohner and Lemaitre [16]. $100 \mathrm{mg}$ of powders were immersed in 10 $\mathrm{mL}$ of SBF for 7 days. At determined time points, the concentration of Se ions was determined by ICP-MS analysis, using a PerkinElmer SCIEXT ELANR DRC-e. The $\mathrm{pH}$ value of SBF during incubation was measured on a Schott CG $842 \mathrm{pH}$-meter using a BlueLine 14 electrode with a precision of $0.01\left(\mathrm{~T}=37.0 \pm 0.5^{\circ} \mathrm{C}\right)$. After incubation, samples were washed in demineralized water and dried at room temperature $\left(\mathrm{T}=23.0 \pm 0.2^{\circ} \mathrm{C}\right)$. Dried samples were mixed with $5 \mathrm{wt} \%$ of polycrystalline silicon (NIST SRN 640e, Sigma Aldrich, St. Louis, MO, USA) and 
an XRD analysis was performed using a Shimadzu XRD-6000 diffractometer in the $2 \theta$ range $3-60^{\circ}$, with a step size of $0.02^{\circ}$ and exposure of $10 \mathrm{~s}$.

\subsection{Anticancer Studies}

\subsubsection{Preparation of Extracts of CaP Powders and Cell Culture Conditions}

To determine selective anticancer properties and biocompatibility of as-prepared powders (CaP_Se0, CaP_Se1, CaP_Se5, CaP_Se10) human embryonic kidney 293 (HEK 293) and human osteosarcoma (U2OS) cells were used. Cells were kindly provided by prof. Inga Urlić, Faculty of Science, University of Zagreb. Non-substituted CaP powder obtained from synthetic $\mathrm{CaCO}_{3}$ as described in [11] was used as control. Calcium phosphate powders were sterilized for 15 min under UV light and incubated with Dulbecco's modified Eagle's culture medium (DMEM) - high glucose (Sigma-Aldrich, St. Louis, MO, USA), supplemented with $10 \%$ fetal bovine serum (Capricorn Scientific, Ebsdorfergrund, Germany) and 1\% penicillin/streptomycin (Lonza, Basel, Switzerland) at a concentration of $10 \mathrm{mg} / \mathrm{mL}$ and kept at $4{ }^{\circ} \mathrm{C}$ for $24 \mathrm{~h}$. After incubation, powders were centrifuged $(300 \times g)$ for $5 \mathrm{~min}$, and the supernatant was used for biocompatibility testing.

The HEK 293 and U2OS cell lines were kept in cell culture conditions $\left(5 \% \mathrm{CO}_{2}\right.$ humidified atmosphere at $37^{\circ} \mathrm{C}$ ) and fed with culture medium until confluence. When they reached $80 \%$ confluence, cells were trypsinized with Trypsin/EDTA (Sigma-Aldrich, St. Louis, MO, USA) to obtain cell suspension. The cells were seeded into each well of a 96-well plate (Corning - Sigma Aldrich, St. Louis, MO, USA) at a concentration of $0.5 \times 10^{5}$ cells per $200 \mu \mathrm{L}$ of the medium and incubated in a $\% \mathrm{CO}_{2}$ humidified atmosphere at $37^{\circ} \mathrm{C}$ for $24 \mathrm{~h}$. After $24 \mathrm{~h}$ cell culture, the medium was removed followed by addition of $200 \mu \mathrm{L}$ of supernatant from calcium phosphate powders to each well.

\subsubsection{Cell Viability Evaluation by MTT Assay}

Viability of HEK 293 and U2OS cells was obtained using MTT (3-(4,5-dimethylthiazol2-yl)-2,5-diphenyltetrazolium bromide) assay (Sigma-Aldrich, St. Louis, MO, USA), after 1 and 3 days of cell treatment with the extract of as-prepared powders. After determined time points, the medium was removed and $40 \mu \mathrm{L}$ of MTT solution was added to each well. After $3 \mathrm{~h}$ at $37^{\circ} \mathrm{C}, 170 \mu \mathrm{L}$ of dimethyl sulfoxide (DMSO, Sigma-Aldrich, St. Louis, MO, USA) was added to each well. When formazan crystals were dissolved, the solution was set for colorimetric detection at $560 \mathrm{~nm}$ using a microplate reader (GlowMax-Multi, Promega, Madison, WI, USA). All experiments were performed in triplicates. The percentage of cell viability was calculated from the absorbance readings in reference to untreated cells.

\subsection{Statistical Analysis}

All biological experiments were conducted in triplicate. Quantitative results are expressed as mean \pm standard error of the mean $(n=3)$. Statistical analysis was performed using one-way ANOVA test with value $p<0.05$ and $p<0.01$ considered statistically significant compared to untreated cells (control).

\section{Results and Discussion}

Selenium-substituted calcium phosphate powders (CaP_Se) were synthesized by wet precipitation method at mild conditions and subjected to chemical, crystallographic and morphological characterization.

\subsection{The Chemical Composition of as-Prepared Powders}

The chemical composition of as-prepared powders was determined by ICP-MS analysis. As shown in Table 2 in addition to $\mathrm{Ca}, \mathrm{P}$ and Se the presence of strontium $\left(\mathrm{Sr}^{2+}\right)$, magnesium $\left(\mathrm{Mg}^{2+}\right)$ and sodium $\left(\mathrm{Na}^{+}\right)$ions has been detected. Using a biogenic source (cuttlefish bone) as a precursor of $\mathrm{Ca}^{2+}$ ions results in a multi-substituted $\mathrm{CaP}$ system as already reported in our previous research [11]. $\mathrm{Sr}^{2+}$ and $\mathrm{Mg}^{2+}$ substitution level is $\sim 0.47$ and $\sim 0.45 \mathrm{~mol} \%$, respectively, while the substitution level of $\mathrm{Na}^{+}$ion increase from 
$1.45 \mathrm{~mol} \%$ (CaP_Se0) to final $3.49 \mathrm{~mol} \%$ (CaP_Se10). Increase of Na-substitution along with the increase of $\mathrm{SeO}_{3}{ }^{2-}$ ion content could be a result of charge defect compensation, since the substitution of a double-charged selenite ion for a triple-charged phosphate ion creates a negatively charged vacancy. The $\mathrm{Sr}^{2+}, \mathrm{Mg}^{2+}$ and $\mathrm{Na}^{+}$are typical substitutional ions for $\mathrm{Ca}^{2+}$ in biological apatites. The $\mathrm{Sr}^{2+}$ ion stimulates the formation of the osteoblast cell line while having an inhibitory effect on osteoclast cells. The $\mathrm{Mg}^{2+}$ ion is an essential element, highly important in the early stage of bone formation due to grow factor effect. Prolonged $\mathrm{Sr}^{2+}$ and $\mathrm{Mg}^{2+}$ deficiency directly result in a decrease in bone density and can cause osteoporosis [17].

Table 2. Results of ICP-MS analysis.

\begin{tabular}{cccccc}
\hline \multirow{2}{*}{ Sample } & \multicolumn{3}{c}{ Minor Substituents (mol\%) } & Se/(P+ Se) Molar Ratio & Ca/(P + Se) Molar Ratio \\
\cline { 2 - 6 } & Sr & Na & Mg & & \\
\hline CaP_Se0 & 0.46 & 1.45 & 0.44 & 0.000 & 1.67 \\
CaP_Se1 & 0.43 & 1.97 & 0.44 & 0.007 & 1.80 \\
CaP_Se5 & 0.48 & 3.23 & 0.46 & 0.029 & 1.68 \\
CaP_Se10 & 0.50 & 3.49 & 0.44 & 0.058 & 1.68 \\
\hline
\end{tabular}

As shown in Table 2, the Se/(P + Se) molar ratios in as-prepared powders increase along with the selenium content added to the reaction mixture. However, the $\mathrm{Se} /(\mathrm{P}+\mathrm{Se})$ molar ratios are lower than the nominal ratios indicating that part of $\mathrm{SeO}_{3}{ }^{2-}$ ions remained in the mother liquor solution after precipitation. The data from Table 2 show that $63.6 \%$ of nominally added $\mathrm{SeO}_{3}{ }^{2-}$ ions were incorporated in CaP_Se1, 59.2\% in CaP_Se5, and 60.4\% in CaP_Se10. Incomplete incorporation of $\mathrm{SeO}_{3}{ }^{2-}$ ions into precipitated calcium phosphates are in accordance with results obtained by Uskoković et al. [9], Wei et al. [10], and Liu et al. [18]. Due to minor substituents, the $\mathrm{Ca} /(\mathrm{P}+\mathrm{Se})$ molar ratio in starting reaction mixture is lower ( 1.61) than the 1.67 required for stoichiometric HAp. In spite of this, for as-prepared powders the values of $\mathrm{Ca} /(\mathrm{P}+\mathrm{Se})$ molar ratios are between 1.67 and 1.80. It can be hypothesized that the incomplete incorporation of selenite ions is compensated by the substitution of $\mathrm{PO}_{4}{ }^{3-}$ with $\mathrm{CO}_{3}{ }^{2-}$, i.e., the formation of type-B carbonated apatites can be expected. As will be shown later, a significant amount of an amorphous phase (ACP) was observed in all as-prepared powders. The $\mathrm{ACP}$ can have a $\mathrm{Ca} / \mathrm{P}$ molar ratio in the range 1.2-2.2, depending on the synthesis conditions and used precursors [4]. As shown in Table 3 the powder CaP_Se1 has the highest content of ACP phase. The higher Ca/P ratio of CaP_Se1 sample, compared to other powders, might be a result of the higher ACP content.

Table 3. Quantitative analysis of CaP phases in as-prepared powders performed by Rietveld refinement of the XRD data and the final $\mathrm{pH}$ values of $\mathrm{CaPs}$ suspensions measured at room temperature $(\mathrm{T}=22.0 \pm 0.5)$.

\begin{tabular}{ccccc}
\hline & & wt $\%$ & pH \\
\hline Sample & HAp & OCP & ACP & \\
\hline CaP_Se0 & 27.8 & 43.9 & 28.3 & 7.60 \\
CaP_Se1 & 61.2 & 8.7 & 30.1 & 8.33 \\
CaP_Se5 & 76.7 & - & 23.3 & 8.63 \\
CaP_Se10 & 77.9 & - & 22.1 & \\
\hline
\end{tabular}

\subsection{XRD Patterns of as-Prepared Powders and Rietveld Refinements}

The XRD patterns of as-prepared non-substituted (CaP_Se0) and Se-substituted (CaP_Se1, CaP_Se5 and CaP_Se10) CaP powders are shown in Figure 1A,B. Samples CaP_Se0 and CaP_Se1 were identified as biphasic mixtures, with a good match to the line patterns for crystalline HAp (JCPDS No.09-0432) and OCP (JCPDS No. 27-1402), while CaP_Se5 and CaP_Se10 show characteristic diffraction peaks for HAp. No additional 
peaks characteristic for selenium compounds were observed. With the increase of the $\mathrm{Se} / \mathrm{P}$ molar ratio, the characteristic diffraction peak intensity and the crystallinity decrease (Figure 1B), which indicates that incorporation of $\mathrm{SeO}_{3}{ }^{2-}$ leads to lattice distortion of obtained CaPs. Compared to the CaP_Se0, the diffraction peaks of the (002) crystal plane of the Se-substituted samples shifted to the left (Figure 1B). The peak shift of the (002) characteristic peak is related to the change of the HAp and/or OCP lattice constant $c$, which means that the incorporation of the $\mathrm{SeO}_{3}{ }^{2-}$ ions has a marked impact on the growth of the HAp crystal, particularly in the $c$-axis direction as previously described by Wei et al. [7].

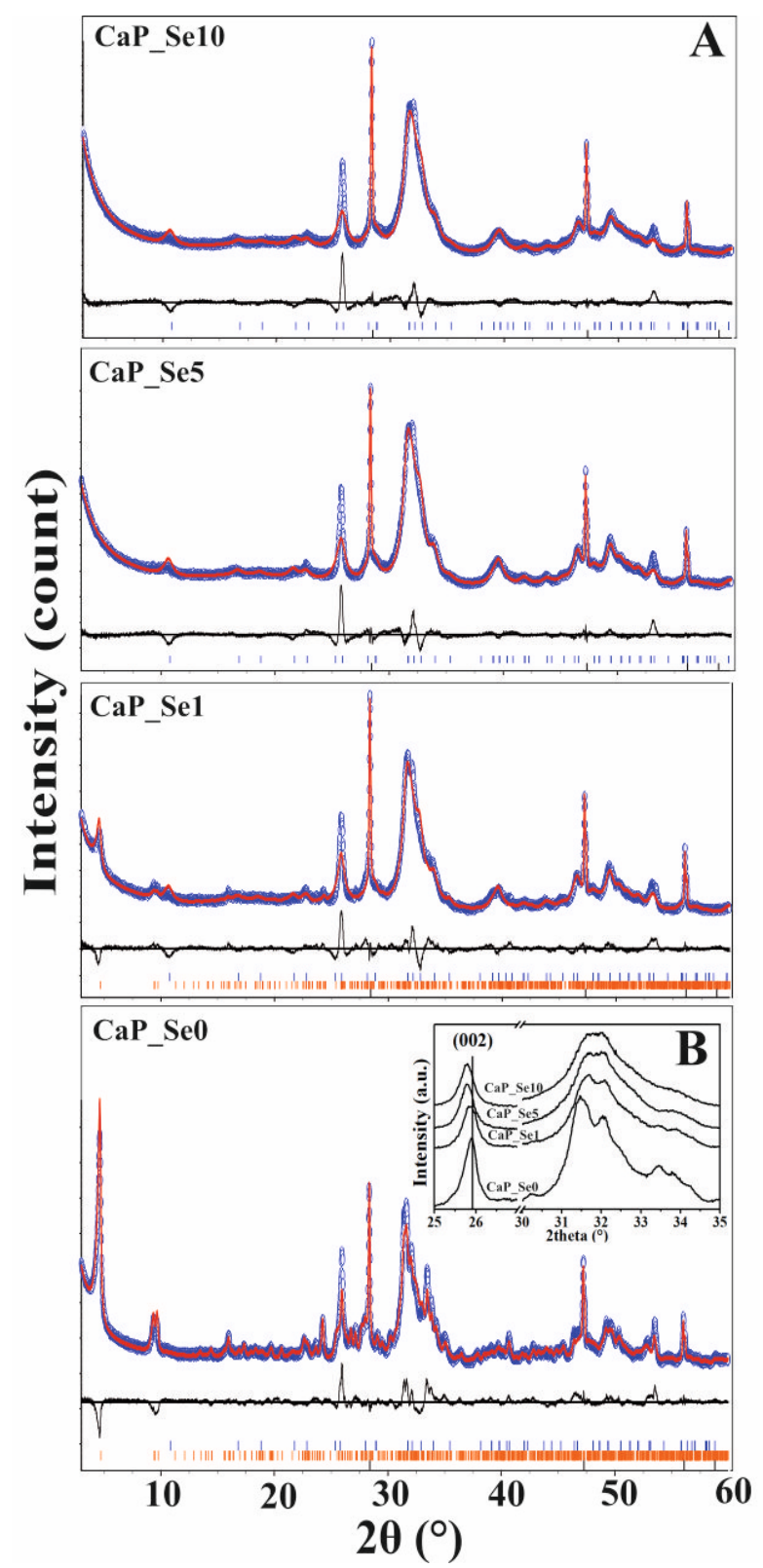

Figure 1. Rietveld analysis of powder X-ray diffraction data (A) and X-ray diffraction analysis patterns (B) for as-prepared non-substituted (CaP_Se0) and Se-substituted (CaP_Se1, CaP_Se5, CaP_Se10) $\mathrm{CaP}$ powders. Observed (blue empty circles) and calculated (red solid lines) intensities. The difference between the observed and calculated intensities is plotted below the profile $\left(\mathrm{R}_{\mathrm{wp}}<10 \%\right.$; $\mathrm{R}_{\exp }<3 \%$ ). Bragg positions of hydroxyapatite, octacalcium phosphate, and silicon (standard) are marked below each pattern.

Rietveld refinement analysis (Figure 1A) was performed on XRD patterns of all prepared samples to determine unit-cell parameters, crystallite size and weight percent 
proportions of detected phases. Results of quantitative analysis of samples are given in Table 3.

The Rietveld refinements indicate a significant amount of an ACP phase in all asprepared powders (Table 3). The CaP_Se0 and CaP_Se1 powders in addition to HAp and ACP phase contain OCP phase as well. The ACP phase is a hydrated, thermodynamically unstable, transient phase that commonly precipitates during the formation of more stable $\mathrm{CaPs}$ in aqueous media. It is considered to be a precursor phase in OCP formation. The OCP is often found as an intermediate phase in the formation of thermodynamically more stable HAp. The final $\mathrm{pH}$ values (Table 3.) of all obtained suspensions were higher than 7. According to the literature [19], the calcium deficient hydroxyapatite $(\mathrm{Ca} / \mathrm{P}=1.5-1.67)$ can be obtained in the $\mathrm{pH}$ range 6.5 to $9.5, \mathrm{OCP}(\mathrm{Ca} / \mathrm{P}=1.33)$ in the $\mathrm{pH}$ range 5.5 to 7.0 and $\mathrm{ACP}(\mathrm{Ca} / \mathrm{P}=1.0-2.2)$ in the $\mathrm{pH}$ range 5.0 to 12.0. The presence of OCP phase within CaP_Se0 and CaP_Se1 systems, even the $\mathrm{pH}$ value was higher than 7.0, suggest that foreign ions influence the phase transformation of calcium phosphates from amorphous to crystalline phases.

The lattice parameters, density, and average crystallite size of the HAp and OCP phase in as-prepared powders, determined by Rietveld refinement of the XRD data, are shown in Table 4.

Table 4. Unit-cell parameters of HAP and OCP phase obtained by Rietveld refinement of the XRD data.

\begin{tabular}{cccccccc}
\hline & \multirow{2}{*}{$\begin{array}{c}\text { Sample } \\
\text { Codes }\end{array}$} & \multicolumn{2}{l}{ Structural Parameters } & & & \\
\cline { 3 - 7 } & & $\mathbf{V}\left(\AA^{\mathbf{3}}\right)$ & $\boldsymbol{a}(\AA)$ & $\boldsymbol{b}(\AA)$ & $\boldsymbol{c}(\AA)$ & $\boldsymbol{\varphi} \mathbf{( g / \mathbf { c m } ^ { 3 } )}$ & $\mathbf{L}(\mathbf{n m})$ \\
\hline \multirow{3}{*}{ HAp } & CaP_Se0 & $529.69(1)$ & 9.41369 & 9.41369 & 6.90197 & 4.233 & 5.15 \\
& CaP_Se1 & $531.69(6)$ & 9.41371 & 9.41371 & 6.87351 & 3.131 & 7.33 \\
& CaP_Se5 & $532.56(5)$ & 9.45098 & 9.45098 & 6.87991 & 3.126 & 6.65 \\
& CaP_Se10 & $533.55(9)$ & 9.45430 & 9.45430 & 6.88637 & 3.120 & 5.79 \\
\hline \multirow{2}{*}{ OCP } & CaP_Se0 & $1220.96(1)$ & 19.69511 & 9.53534 & 6.85167 & 2.780 & 33.85 \\
& CaP_Se1 & $1226.91(8)$ & 19.71504 & 9.50590 & 6.89569 & 2.660 & 18.19 \\
\hline
\end{tabular}

The variation of unit cell parameters of HAp phase as a function of Se/(P + Se) molar ratio in as prepared powders is shown in Figure 2.

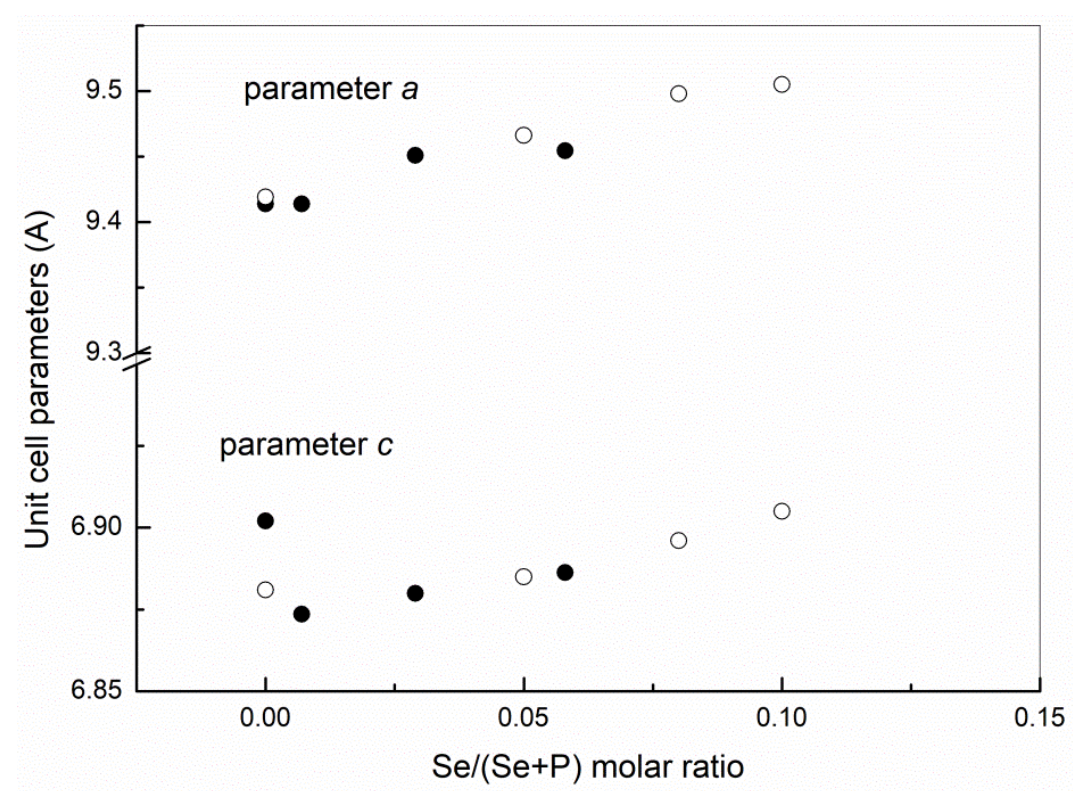

Figure 2. Unit cell parameters of HAp phase as a function of Se/(P+Se) molar ratio in as-prepared powders (black circles) compared to the literature data [20] (empty circles). 
Lattice parameter $a(=b)$ increases with increasing Se-substitution, which can be explained by the larger bond length of Se-O $(0.164 \mathrm{~nm})$ compared to P-O bond length $(0.155$ $\mathrm{nm})$. The unit cell parameter $c$ of substituted HAp phase in all prepared powders is lower than $c$ of non-substituted HAp but exhibited an increase with the Se substitution level. The lower value of the lattice parameter $c$ in substituted HAp, compared to non-substituted HAps, may indicate the release of hydroxyl groups and formation of vacancies along the $c$ axis due to charge compensation since $\mathrm{SeO}_{3}{ }^{2-}$ (double charged) substitute $\mathrm{PO}_{4}{ }^{3-}$ ion (triple charged), that consequently leads to $\mathrm{Ca}^{2+}$ and $\mathrm{OH}^{-}$ion release [21,22]:

$\mathrm{Ca}_{10}\left(\mathrm{PO}_{4}\right)_{6}(\mathrm{OH})_{2}+x \mathrm{SeO}_{3}{ }^{2-} \rightarrow \mathrm{Ca}_{10-x}\left(\mathrm{PO}_{4}\right)_{6-x}\left(\mathrm{SeO}_{3}\right)_{x}(\mathrm{OH})_{2-x}+x \mathrm{PO}_{4}{ }^{3-}+x \mathrm{Ca}^{2+}+x \mathrm{OH}^{-}$

The difference between the $c$ parameters of non-substituted and Se-substituted HAps is smaller for higher Se-substitution levels, where the higher content of $\mathrm{Na}^{+}$ions was detected, indicating additional charge defect compensation by Na-substitution for $\mathrm{Ca}$ according to the formula $\mathrm{Ca}_{10-x} \mathrm{Na}_{x}\left(\mathrm{PO}_{4}\right)_{6-x}\left(\mathrm{SeO}_{3}\right)_{x}(\mathrm{OH})_{2}$. The lattice parameters of substituted samples compare fairly well with the literature data reported by Barbanente et al. [20], showing an almost linear rise of cell parameters with Se substitution up to a Se $/(\mathrm{P}+\mathrm{Se})$ molar ratio of 0.1 (Figure 2). Wei et al. [10] reported that $a$ and $b$ lattice parameters increase along with the Se-substitution level, while lattice parameter $c$ decreases, while Sun et al. [21] reported a non-continuous change of $a$ and $b$ and decrease of $c$ lattice parameters. Kolmas et al. [22] observed an increase of $a$ and $b$ and non-continuous change of $c$ lattice parameters along with the Se-substitution level. The difference in the unit cell paramter $c$ between the non-substituted (CaP_Se0) powder prepared in this work and those reported in the literature can be attributed to the biogenic precursor (cuttlefish bone) used in this work. The cuttlefish bone in its aragonite structure contains a significant amount of trace elements (e.g., $\mathrm{Sr}^{2+}, \mathrm{Mg}^{2+}, \mathrm{Na}^{+}$) that can influence the unit cell parameters of prepared CaPs.

As seen from Table 4, in spite of lower values of parameter $c$ in substituted HAp, the unit cell volume, V, of the HAp phase in the prepared samples increases and the density consequently decreases with the Se-substitution level. Selenite ion (trigonal pyramidal) has greater volume compared to phosphate ion (tetrahedral) and consequently, the substitution may result in the dilatant unit cell and oxygen voids may be generated [10]. Very small difference in the average crystallite size L (ranging between 5 and $7 \mathrm{~nm}$ ) was obtained for the HAp phase in the prepared non-substituted and Se-substituted samples.

The unit cell parameters, unit cell volume, and the average crystallite size of OCP phase in the powder CaP_Se1 differ from the values obtained for non-substituted CaP_Se0 powder, indicating the incorporation of selenite ions in the OCP phase, too. Since the powders CaP_Se5 and CaP_Se10 do not contain an OCP phase, the proper correlation between the mentioned parameters and selenite substitution level cannot be established. It should be noted that the Rietveld refinement is not sensitive enough to determine selenite concentration in each (HAp and OCP) phase.

\subsection{XRD Patterns of Heat Treated Powders and Rietveld Refinements}

XRD patterns of heat treated powders at $1200{ }^{\circ} \mathrm{C}$ are presented in Figure 3.

Compared to the XRD patterns of as-prepared samples, XRD patterns sharpen after heat treatment, indicating an increase of crystallinity. The XRD data of the sample CaP_Se0 gave a good match to the line pattern of $\beta$-TCP (JCPDS No. 09-0169). Samples CaP_Se1, CaP_Se5, and CaP_Se10 were identified as triphasic mixtures with a good match to the patterns of HAp (JCPDS No.09-0432), $\beta$-TCP, and $\alpha$-TCP (JCPDS No. 09-0348). Results of the quantitative phase analysis of the heat-treated samples determined by Rietveld refinement of the XRD data are given in Table 5. 


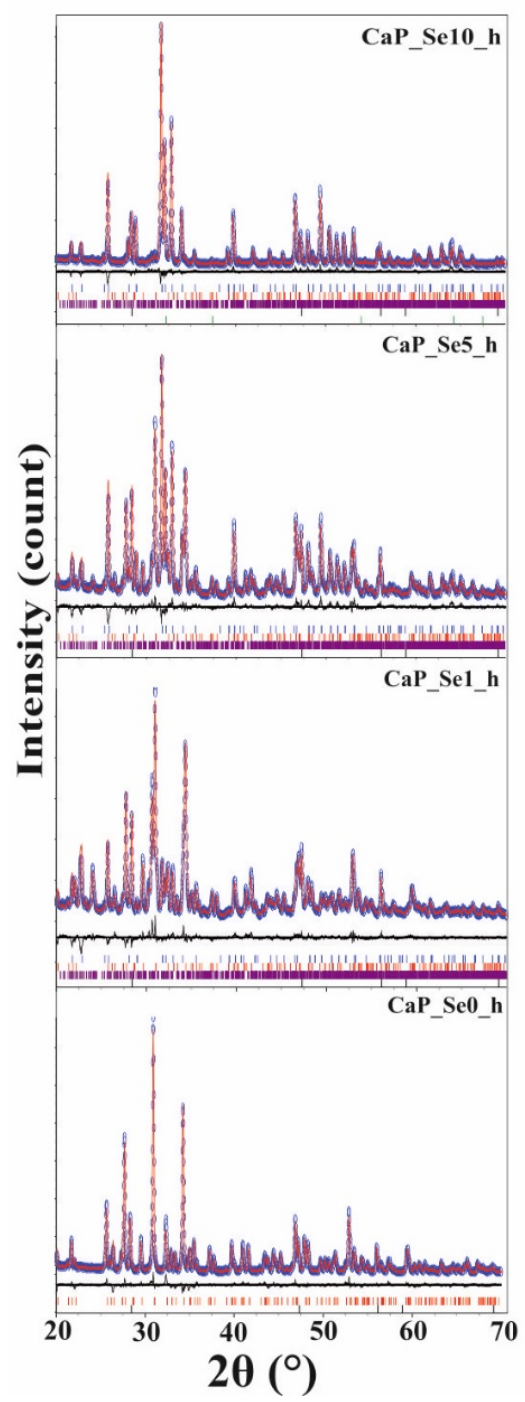

Figure 3. Rietveld analysis pattern of powder diffraction data for heat treated $\mathrm{CaP}$ powders. Observed (blue empty circles) and calculated (red solid lines) intensities. The difference between the experimental and calculated intensities is plotted below the profile $\left(R_{w p}<11 \% ; R_{\exp }<3 \%\right)$. Bragg positions of hydroxyapatite, $\beta$-tricalcium phosphate, $\alpha$-tricalcium phosphate, and silicon (standard) are marked below each pattern.

Table 5. Results of quantitative analysis of the heat treated CaP powders performed by Rietveld refinement of the XRD data.

\begin{tabular}{cccccc}
\hline \multirow{2}{*}{ Sample } & \multicolumn{5}{c}{$\mathbf{w t \%}$} \\
\cline { 2 - 6 } & HAp & $\boldsymbol{\beta}$-TCP & $\boldsymbol{\alpha}$-TCP & ACP & CaO \\
\hline CaP_Se0 & - & 88.6 & - & 11.4 & - \\
CaP_Se1 & 10.6 & 50.4 & 32.5 & 6.5 & - \\
CaP_Se5 & 45.8 & 36.6 & 9.8 & 7.8 & - \\
CaP_Se10 & 88.2 & 3.1 & 4.1 & 4.4 & 0.2 \\
\hline
\end{tabular}

With the increase of selenite ion content, an increase in the HAp content and a decreasing trend in $\beta$-TCP and $\alpha$-TCP content have been observed. Similar findings that the incorporation of selenite ions restricts the phase transformation from HAp to $\beta$-TCP are reported in the literature $[7,10,23]$. As observed by Wei et al. [10] the samples with $\mathrm{Se} / \mathrm{P} \leq 0.05 \mathrm{did}$ not transform to the TCP phase after heat treatment at $1100{ }^{\circ} \mathrm{C}$. 
As seen from Table 5 in the heat-treated sample CaP_Se10 CaO phase was detected, as well. Wei et al. [10] observed $\mathrm{CaO}$ as secondary phase after high-temperature sintering of the sample prepared with a Se/P molar ratio of 0.08 . They speculate that the $\mathrm{CaO}$ is formed by transformation of $\mathrm{CaSeO}_{3}$ that eventually precipitates in a very small amount and cannot be detected by XRD.

\subsection{FTIR Analysis}

The FTIR spectra of as-prepared and heat treated CaP powders are shown in Figure 4A,B, respectively.

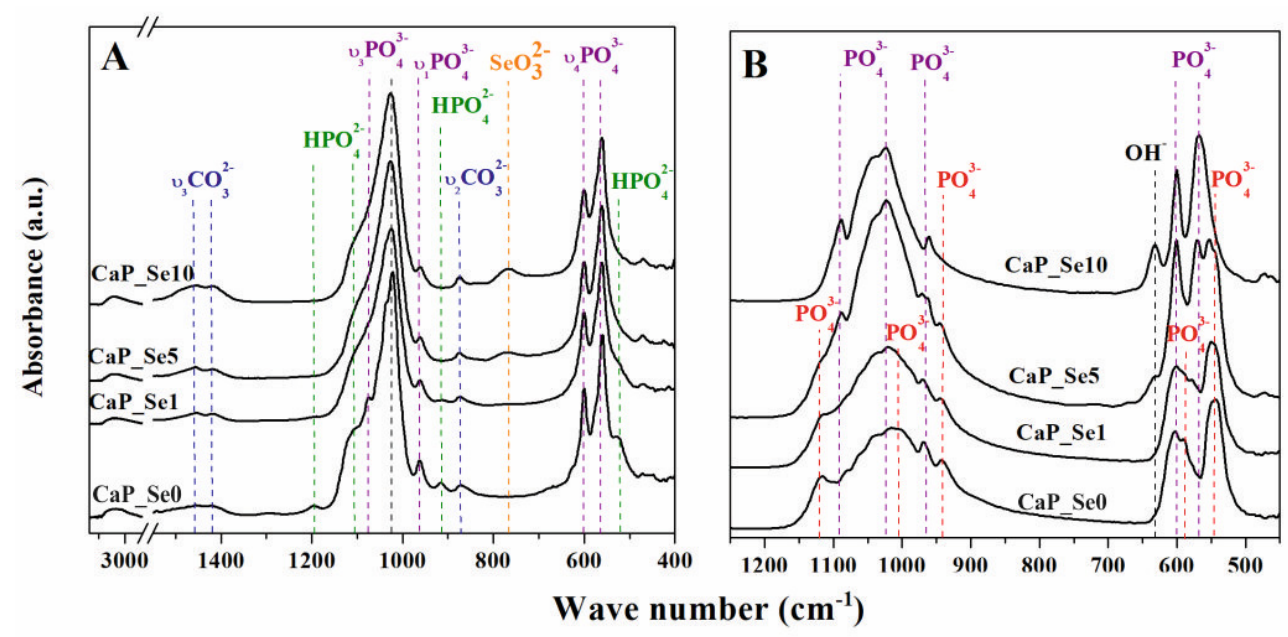

Figure 4. FTIR spectra of as-prepared (A) and heat-treated (B) non-substituted (CaP_Se0) and Se-substituted (CaP_Se1, CaP_Se5, CaP_Se10) CaP powders.

FTIR spectra of as-prepared samples show broad bands in the range $3000-3700 \mathrm{~cm}^{-1}$, attributed to adsorbed water. The strong bands in the range $900-1200 \mathrm{~cm}^{-1}$ correspond to characteristic stretching vibration modes of the phosphate group. The bands at 1022 and $1074 \mathrm{~cm}^{-1}\left(v_{3}\right)$ are attributed to the asymmetric stretching vibration of $\mathrm{P}-\mathrm{O}$, at $964 \mathrm{~cm}^{-1}\left(v_{1}\right)$ is associated with the symmetric stretching vibration of $\mathrm{P}-\mathrm{O}$, and at 565 and $599\left(v_{4}\right) \mathrm{cm}^{-1}$ are attributed to asymmetric bending vibrations of $\mathrm{O}-\mathrm{P}-\mathrm{O}$, all of which can be assigned to the HAp phase [24]. Absorption bands at 525, 912, 1112, and $1193 \mathrm{~cm}^{-1}$, which are attributed to the characteristic absorption bands of a $\mathrm{HPO}_{4}{ }^{2-}$ group, can be assigned to the OCP and ACP phases [25-29]. The intensities of $\mathrm{HPO}_{4}{ }^{2-}$ bands decrease along with the increase of Se-substitution level, since the content of OCP and ACP phase decrease, as well. The bands at 875,1419 , and $1463 \mathrm{~cm}^{-1}$ are characteristic vibration modes for carbonate groups substituted for phosphate group (B-type substitution) [30,31]. $\mathrm{CO}_{3}{ }^{2-}$ substitution was expected since $\mathrm{CaCO}_{3}$ was used as the source of Ca-ions. Additionally, it could be the result of $\mathrm{CO}_{2}$ dissolution in the reaction medium during the open-air synthesis. The band at $765 \mathrm{~cm}^{-1}$ is attributed to O-Se-O bending vibration $\left(v_{3}\right)$ and it becomes stronger as the Se-substitution level increases [22]. The characteristic vibration modes for Se-O bands are in the range of $900-800 \mathrm{~cm}^{-1}$ [23]. However, they overlap with vibration modes of carbonate groups. Obtained results indicate that prepared samples are co-substituted with $\mathrm{SeO}_{3}{ }^{2-}$ and $\mathrm{CO}_{3}{ }^{2-}$ in the position of $\mathrm{PO}_{4}{ }^{3-}$ ions. $\mathrm{CO}_{3}{ }^{2-}$ ions are considered to be more easily incorporated into the HAp lattice due to having a smaller volume than $\mathrm{SeO}_{3}{ }^{2-}$ ions $[10,32]$.

In the FTIR spectra of the heat-treated samples (Figure $4 \mathrm{~B}$ ) the band at $631 \mathrm{~cm}^{-1}$ is assigned to the hydroxyl group of HAp. Its intensity increases as the Se/P ratio increases, in agreement with the quantitative analysis of the heat-treated $\mathrm{CaP}$ powders performed by Rietveld refinement of the XRD data that shows stabilization of the HAp phase during the heat treatment process. Characteristic P-O bands of HAp appear at 1090, 1023, 965, 600 , and $568 \mathrm{~cm}^{-1}$. A broad band from 950 to $1200 \mathrm{~cm}^{-1}$ corresponds to the TCP phases. 
The bands at 1120 and $1004 \mathrm{~cm}^{-1,}$ attributed to stretching vibration of P-O, at $940 \mathrm{~cm}^{-1}$, associated with banding modes of P-O, at 1040, 1062, and $1082 \mathrm{~cm}^{-1}\left(v_{3}\right)$, attributed to anti-symmetric P-O stretching, and at 542,588 , and $600 \mathrm{~cm}^{-1}\left(v_{3}\right)$, attributable to anti-symmetric P-O bending can be assigned to $\beta$-TCP phase. The bands at 940 and $965 \mathrm{~cm}^{-1}$ arise due to the factor group splitting of the $v_{1}$ fundamental vibration mode corresponding to the symmetric $\mathrm{P}-\mathrm{O}$ stretching vibration of the phosphate ion $\left(958 \mathrm{~cm}^{-1}\right)$. The characteristic bands for $\beta$-TCP are similar to bands of $\alpha$-TCP, however, the latter are broader [33]. This effect can be seen in the FTIR spectrum for CaP_Se1 compared to CaP_Se0 powder. Characteristic band at $765 \mathrm{~cm}^{-1}$, attributed to O-Se-O bending vibration, disappears as a result of decomposition of selenite with the release of $\mathrm{SeO}_{2}$ in gas form as previously reported by Wei et al. [10].

\subsection{SEM Analysis}

SEM micrographs of as-prepared powders are given in Figure 5, showing both spherical particles and irregularly shaped agglomerates. The surface of particles in CaP_Se0 and CaP_Se1 powders exhibited plate like morphology, typical for OCP and frequently observed for synthetic and natural apatites. It seems that the higher Se-substitution level in CaP_Se5 and CaP_Se10 samples resulted in a reduced particle size and the plate like crystals on the particle surface are less evident.

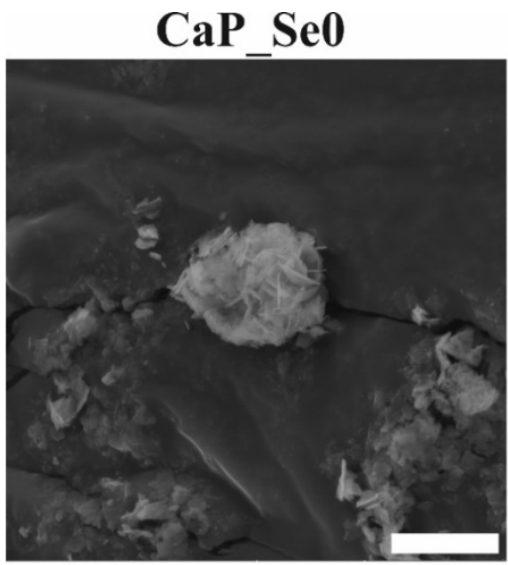

CaP Se5

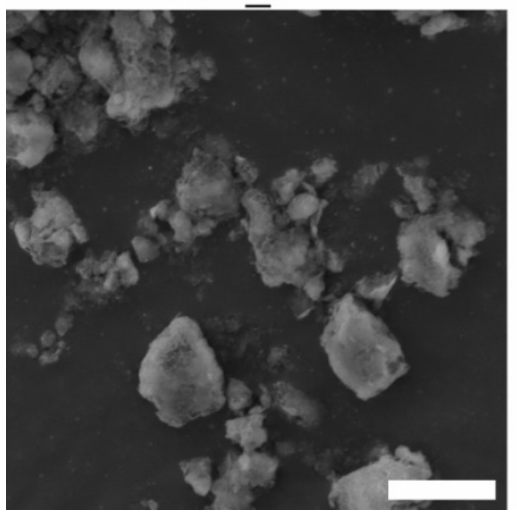

\section{CaP Se1}

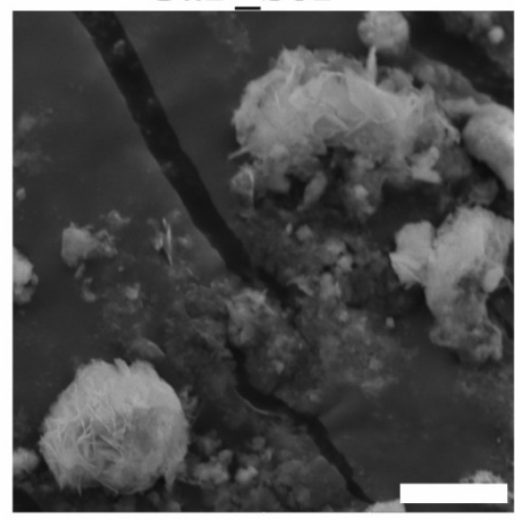

CaP Se10

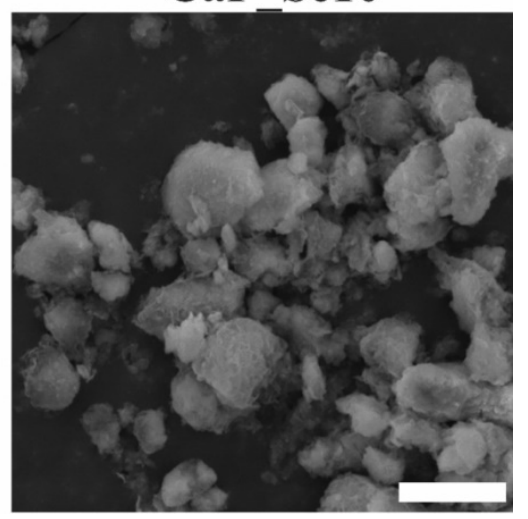

Figure 5. SEM micrographs of as-prepared CaP powders. Scale bars: $5 \mu \mathrm{m}$.

From the obtained SEM images, it is difficult to estimate the average size of the particles since they are not well dispersed. It seems that a fraction of particles settled at the bottom, and it is difficult to distinguish between particle boundaries. The size of spherical agglomerates in CaP_Se0 and CaP_Se1 powders is around $5 \mu \mathrm{m}$, while the agglomerates in CaP_Se5 and CaP_Se10 powders are smaller than $5 \mu \mathrm{m}$. 


\subsection{Ion Release and In Vitro Bioactivity}

The dissolution of the as-prepared powders and their ability to form apatite like phases in simulated body conditions were followed by ICP-MS and XRD analysis. Release curve of selenite ions for $\mathrm{CaP} \_$Se5 powder shown in Figure 6 indicate an initial burst release (day 1) followed by a stage of slow and mostly steady release. The $\mathrm{pH}$ value of the SBF solution varied slightly during incubation time from an initial 7.40 to a maximum of 7.66.

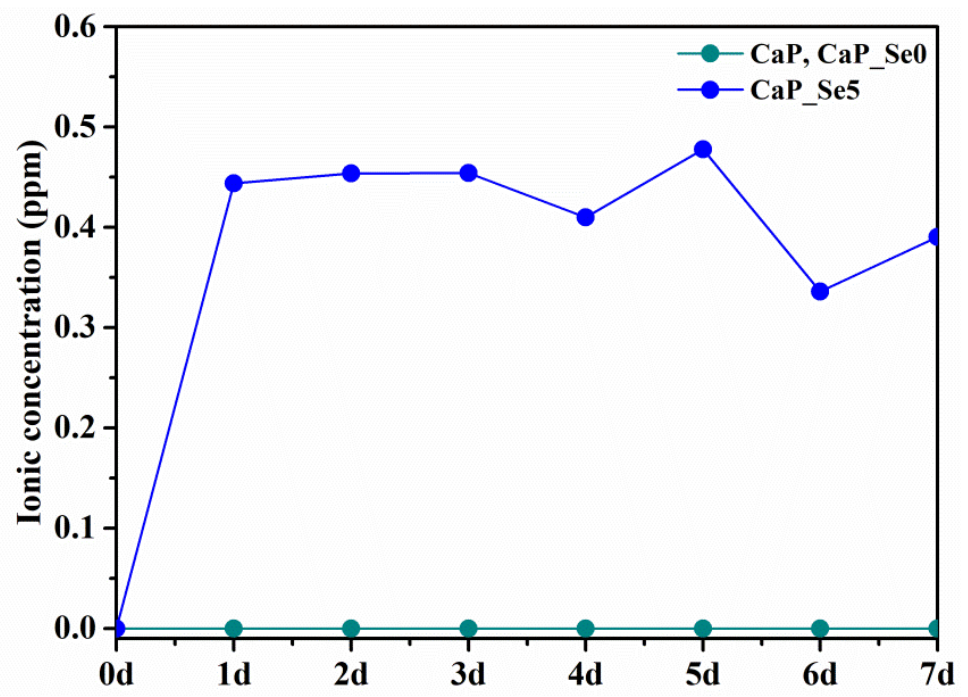

Figure 6. Released $\mathrm{SeO}_{3}{ }^{2-}$ ion concentration during 7 days of incubation at $37^{\circ} \mathrm{C}$.

The concentration of released Se ion is the same for $\mathrm{CaP}$ and CaP_Se0 powder (selenitefree samples, 0 ppm, green line in Figure 6).

Results of quantitative XRD analysis of the powders CaP_Se0 and CaP_Se 5 after 7 days of immersion in SBF, performed by Rietveld refinement, are given in Table 6.

Table 6. Results of quantitative analysis of powders after soaking in SBF compared to asprepared powders.

\begin{tabular}{ccccccc}
\hline & \multicolumn{3}{c}{ As-Prepared Powders } & \multicolumn{3}{c}{ After Soaking in SBF } \\
\hline Sample & HAp & OCP & ACP & HAp & OCP & ACP \\
\hline CaP_Se0 & 27.8 & 43.9 & 28.3 & 45.0 & 27.9 & 27.1 \\
CaP_Se5 & 76.7 & - & 23.3 & 86.3 & - & 13.7 \\
\hline
\end{tabular}

As seen, during soaking the partial transformation of OCP and ACP phases into the HAp phase occurred. When apatite samples are immersed in SBF, both dissolution and the precipitation of apatite occurs simultaneously. SBF solution contains calcium, phosphate and carbonate ions, the concentrations of which are close to the solubility limit of carbonated HAp. The dissolution and liberation of ions can result in localized supersaturation that favors precipitation of carbonated HAp. From XRD patterns it was not possible to distinguish between the original powder phases and the newly formed apatite phase.

\subsection{Selective Anticancer Activity of Selenium Substituted Calcium Phosphates}

The main goal of preparing selenium substituted CaPs is obtaining a biomaterial that will effectively inhibit the development of bone cancers while showing no cytotoxic activity on healthy cells. The cell viability results are given in Figure 7. 

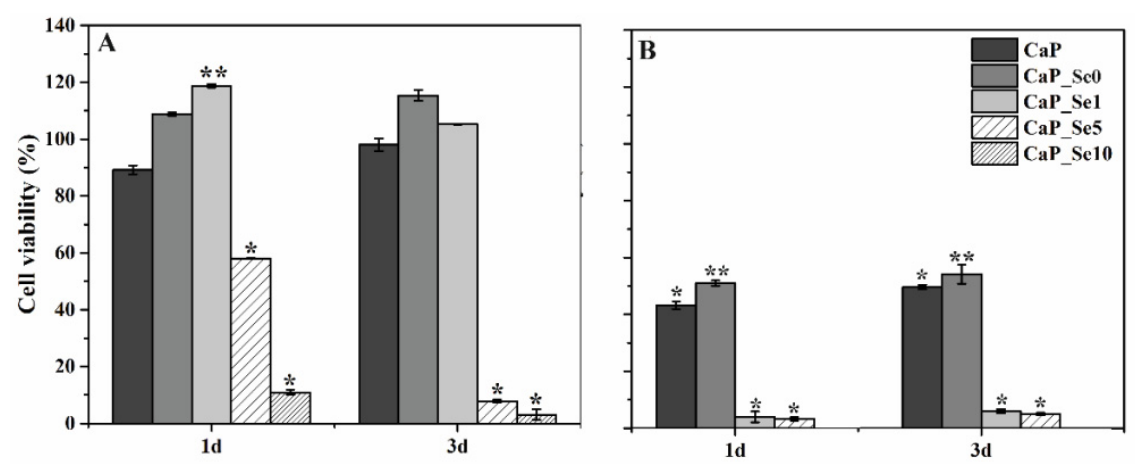

Figure 7. The effect of supernatant of calcium phosphate powders on cell viability (\%) of HEK 293 (A) and U2OS (B) cells, respectively. The significant difference between two groups: ${ }^{* *}(p<0.05)$, * $(p<0.01)$.

Figure 7A shows that in comparison with the control group (untreated cells), in which cell viability was estimated to be $100 \%$, extracts of CaP_Se0 and CaP_Se1 powders exert a proliferative effect on the HEK 293 cells. The higher cell viability for CaP_Se0 compared to $\mathrm{CaP}$ (non-substituted $\mathrm{CaP}$ powder obtained from synthetic $\mathrm{CaCO}_{3}$ ) indicates a beneficial effect of foreign ions present in the biogenic Ca-ion precursor on cell proliferation. The treatment with extracts of CaP_Se5 for 1 and 3 days reduced HEK 293 cell viability by 40 and $\sim 90 \%$, respectively, while the CaP_Se10 powder reduced HEK 293 cell viability by $\sim 90 \%$ or more, at both time points. The anticancer activity was examined using U2OS cell line. As Figure 7B shows, the cell proliferation was significantly suppressed in the presence of the extracts of all investigated powders. The extracts of $\mathrm{CaP}$ and $\mathrm{CaP} \_\mathrm{Se} 0$ powders caused a significant reduction in the U2OS cell viability ( $50 \%$ and $54 \%$, respectively) while the extracts of the CaP_Se1 and CaP_Se5 powders reduced U2OS cell viability by more than $95 \%$ compared to untreated cells.

Uskoković et al. [9] also reported that the viability of K7M2 osteosarcoma cells decreased in direct proportion to the amount of selenite in HAp but no reduction was observed in the viability of primary fibroblasts treated with HAp incorporating different amounts of selenite ions, suggesting their potentially selective anticancer activity. Our results suggest that only the CaP_Se1 powder, with low concentration of Se, show selective toxicity to cancer cells (U2OS), without harming non-tumorigenic cells (HEK 293) cells. Results are consistent with the study of Barbanente et al. [20], who evaluated the cytotoxic activity of Se-doped HAp nano particles using prostate and breast cancer cells as well as healthy human bone marrow stem cells. They found that nanoparticles with a high concentration of Se showed a strong anticancer effect but also caused a significant increase in toxicity towards normal cells.

Additional in vitro osteogenic cell culture experiments and in vivo studies are needed to confirm the suitability of investigated materials for potential application in bone tumor therapy. Furthermore, in our future research, highly porous scaffolds based on a biopolymer and selenite substituted CaPs will be prepared and characterized.

\section{Conclusions}

In the present study, Se-substituted calcium phosphates have been prepared via an aqueous precipitation reaction at mild conditions. As a result of using biogenic source (cuttlefish bone) as a precursor of $\mathrm{Ca}^{2+}$ ions along with the selenite substitution, the presence of $\mathrm{Sr}^{2+}, \mathrm{Na}^{+}$, and $\mathrm{Mg}^{2+}$ was detected by ICP-MS analysis. The selenium ion concentration affects the phase composition of obtained powders, consisting of calcium deficient bone-like HAp, OCP, and ACP. The presence of selenium ions in as-prepared powders stabilizes the HAp phase during heat treatment at $1200{ }^{\circ} \mathrm{C}$. The CaP_Se1powder with the $\mathrm{Se} /(\mathrm{P}+\mathrm{Se})$ molar ratio of 0.007 showed selective toxicity to cancer cells. The treatment with extracts of CaP_Se5 powder $(\mathrm{Se} /(\mathrm{P}+\mathrm{Se})$ molar ratio of 0.029$)$ for 1 and 3 days reduced HEK 293 cell viability for $\sim 40$ and $\sim 90 \%$, respectively. The CaP_Se10 
powder with Se/(P + Se) molar ratio of 0.058 reduced HEK 293 cell viability for $\sim 90 \%$ at both time points. The extracts of $\mathrm{CaP}$ and $\mathrm{CaP} \_\mathrm{Se} 0$ (selenium-free) powders caused a significant reduction in the U2OS cell viability ( $50 \%$ and $54 \%$, respectively) while the extracts of the CaP_Se1 and CaP_Se5 powders reduced U2OS cell viability by more than $95 \%$, compared to untreated cells.

Author Contributions: Conceptualization, M.I. and H.I.; methodology, A.R. and H.I.; software, A.R.; validation, A.R., M.A. and M.C.; formal analysis, A.R., M.A. and M.C.; investigation, A.R., M.A. and M.C.; resources, M.I. and H.I.; data curation, A.R.; writing—original draft preparation, A.R.; writing-review and editing, M.I.; visualization, A.R. and M.I.; supervision, M.I. and H.I.; project administration, H.I.; funding acquisition, M.I. and H.I. All authors have read and agreed to the published version of the manuscript.

Funding: This research was funded by the European Regional Development Fund (grant KK.01.1.1.07. 0014.).

Institutional Review Board Statement: Not applicable.

Informed Consent Statement: Not applicable.

Data Availability Statement: Data sharing is not applicable to this article.

Acknowledgments: The financial support of L'Oréal-UNESCO Foundation 'For Women in Science' are gratefully acknowledged. The authors thank Inga Urlić, Faculty of Science, University of Zagreb for providing HEK 293 and U2OS cells.

Conflicts of Interest: The authors declare no conflict of interest.

\section{References}

1. Pajor, K.; Pajchel, L.; Kolodziejska, B.; Kolmas, J. Selenium-Doped Hydroxyapatite Nanocrystals-Synthesis, Physicochemical Properties and Biological Significance. Crystals 2018, 8, 188. [CrossRef]

2. Habraken, W.; Habibovic, P.; Epple, M.; Bohner, M. Calcium phosphates in biomedical applications: Materials for the future? Mater. Today 2016, 19, 69-87. [CrossRef]

3. Safarzadeh, M.; Ramesh, S.; Tan, C.Y.; Chandran, H.; Mohd Noor, A.F.; Krishnasamy, S.; Johnson Alengaram, U.; Ramesh, S. Effect of multi-ions doping on the properties of carbonated hydroxyapatite bioceramics. Ceram. Int. 2018, 45, 3473-3477. [CrossRef]

4. Boanini, E.; Gazzano, M.; Bigi, A. Ionic substitutions in calcium phosphates synthesized at low temperature. Acta Biomater. 2010, 6, 1882-1894. [CrossRef]

5. Pang, K.L.; Chin, K.Y. Emerging Anticancer Potentials of Selenium on Osteosarcoma. Int. J. Mol. Sci. 2019, 20, 5318. [CrossRef]

6. Wang, Y.; He, W.; Hao, H.; Wu, J.; Qin, N. Eggshell derived Se-doped HA nanorods for enhanced antitumor effect and curcumin delivery. J. Sol-Gel Sci. Technol. 2018, 87, 600-607. [CrossRef]

7. Wei, L.; Yang, H.; Hong, J.; He, Z.; Deng, C. Synthesis and structure properties of Se and Sr co-doped hydroxyapatite and their biocompatibility. J. Mater. Sci. 2019, 54, 2514-2525. [CrossRef]

8. Wang, Y.; Wang, J.; Hao, H.; Cai, M.; Wang, S.; Ma, J.; Li, Y.; Mao, C.; Zhang, S. In vitro and in vivo mechanism of bone tumor inhibition by selenium-doped bone mineral nanoparticles. ACS Nano 2016, 10, 9927-9937. [CrossRef] [PubMed]

9. Uskoković, V.; Adiraj Iyer, M.; Wu, V.M. One ion to rule them all: The combined antibacterial, osteoinductive and anticancer properties of selenite-incorporated hydroxyapatite. J. Mater. Chem. B 2017, 5, 1430-1445. [CrossRef]

10. Wei, L.; Pang, D.; He, L.; Deng, C. Crystal structure analysis of selenium-doped hydroxyapatite samples and their thermal stability. Ceram. Int. 2017, 43, 16141-16148. [CrossRef]

11. Ressler, A.; Cvetnić, M.; Antunović, M.; Marijanović, I.; Ivanković, M.; Ivanković, H. Strontium substituted biomimetic calcium phosphate system derived from cuttlefish bone. J. Biomed. Mater. Res. B 2020, 108, 1697-1709. [CrossRef]

12. Veselinović, L.; Karanović, L.; Stojanović, Z.; Bračko, I.; Marković, S.; Ignjatović, N.; Uskoković, D. Crystal structure of cobaltsubstituted calcium hydroxyapatite nanopowders prepared by hydrothermal processing. J. Appl. Cryst. 2010, 43, 320-327. [CrossRef]

13. Espanol, M.; Portillo, J.; Manero, J.M.; Ginebra, M.P. Investigation of the hydroxyapatite obtained as hydrolysis product of a-tricalcium phosphate by transmission electron microscopy. Cryst. Eng. Commun. 2010, 12, 3318-3326. [CrossRef]

14. Yashima, M.; Sakai, A.; Kamiyama, T.; Hoshikawa, A. Crystal structure analysis of $\beta$-tricalcium phosphate Ca3(PO4)2 by neutron powder diffraction. J. Solid State Chem. 2003, 175, 272-277. [CrossRef]

15. Mathew, M.; Brown, W.E.; Schroeder, L.W.; Dickens, B. The crystal structure of alpha-Ca3(PO4)2. Acta Crystallogr. B 1977, 33, 1325-1333. [CrossRef]

16. Bohner, M.; Lemaitre, J. Can bioactivity be tested in vitro with SBF solution? Biomaterials 2009, 30, 2175-2179. [CrossRef] 
17. Bose, S.; Fielding, G.; Tarafder, S. Bandyopadhyay, Understanding of Dopant-Induced Osteogenesis and Angiogenesis in Calcium Phosphate Ceramics. Trends Biotechnol. 2013, 10, 594-605. [CrossRef]

18. Liu, Y.; Ma, J.; Zhang, S. Synthesis and thermal stability of selenium-doped hydroxyapatite with different substitutions. Front. Mater. Sci. 2015, 9, 392-396. [CrossRef]

19. Dorozhkin, S.V. Amorphous calcium (ortho)phosphates. Acta Biomater. 2010, 6, 4457-4475. [CrossRef] [PubMed]

20. Barbanente, A.; Palazzo, B.; Degli Esposti, L.; Adamiano, A.; Iafisco, M.; Ditaranto, N.; Migoni, D.; Gervaso, F.; Nadar, R.; Ivanchenko, P.; et al. Selenium-doped hydroxyapatite nanoparticles for potential application in bone tumor therapy. J. Inorg. Biochem. 2021, 215, 111334. [CrossRef] [PubMed]

21. Sun, J.; Zheng, X.; Li, H.; Fan, D.; Song, Z.; Ma, H.; Hua, X.; Hui, J. Monodisperse selenium-substituted hydroxyapatite: Controllable synthesis and biocompatibility. Mater. Sci. Eng. C 2017, 73, 596-602. [CrossRef]

22. Kolmas, J.; Oledzka, E.; Sobczak, M.; Nałęcz-Jawecki, G. Nanocrystalline hydroxyapatite doped with selenium oxyanions: A new material for potential biomedical applications. Mater. Sci. Eng. C 2014, 39, 134-142. [CrossRef]

23. Ma, L.; Wang, Y.; Zhou, L.; Zhang, S. Preparation and characterization of selenite substituted hydroxyapatite. Mater. Sci. Eng. C 2013, 33, 440-445. [CrossRef]

24. Moreira, M.P.; de Almeida Soares, G.D.; Dentzer, J.; Anselme, K.; de Sena, L.A.; Kuznetsov, A.; dos Santos, E.A. Synthesis of magnesium- and manganese-doped hydroxyapatite structures assisted by the simultaneous incorporation of strontium. Mater. Sci. Eng. C 2016, 62, 736-743. [CrossRef]

25. Gao, J.; Wang, M.; Shi, C.; Wang, L.; Zhu, Y.; Wang, D. A facile green synthesis of trace Si, Sr and F multi-doped hydroxyapatite with enhanced biocompatibility and osteoconduction. Mater. Lett. 2017, 196, 406-409. [CrossRef]

26. Ravi, N.D.; Balu, R.; Kumar, T.S.S. Strontium-substituted calcium deficient hydroxyapatite nanoparticles: Synthesis, characterization, and antibacterial properties. J. Am. Ceram. Soc. 2012, 95, 2700-2708. [CrossRef]

27. Rogina, A.; Rico, P.; Gallego Ferrer, G.; Ivanković, M.; Ivanković, H. Effect of in situ formed hydroxyapatite on microstructure of freeze-gelled chitosan-based biocomposite scaffolds. Eur. Polym. J. 2015, 68, 278-287. [CrossRef]

28. Shi, H.; He, F.; Ye, J. Synthesis and structure of iron- and strontium-substituted octacalcium phosphate: Effects of ionic charge and radius. J. Mater. Chem. B 2016, 4, 1712-1719. [CrossRef] [PubMed]

29. Terra, J.; Dourado, E.R.; Eon, J.G.; Ellis, D.E. The structure of strontium-doped hydroxyapatite: An experimental and theoretical study. Phys. Chem. Chem. Phys 2009, 11, 568-577. [CrossRef]

30. Gibson, I.R.; Bonfield, W. Novel synthesis and characterization of an AB-type carbonate-substituted hydroxyapatite. J. Biomed. Mater. Res. 2002, 59, 697-708. [CrossRef] [PubMed]

31. Lafon, J.P.; Champion, E.; Bernache-Assollant, D. Processing of AB-type carbonated hydroxyapatite $\mathrm{Ca}_{10-\mathrm{x}}\left(\mathrm{PO}_{4}\right)_{6-\mathrm{x}}\left(\mathrm{CO}_{3}\right)_{\mathrm{x}}(\mathrm{OH})_{2-\mathrm{x}-2 \mathrm{y}}$ $\left(\mathrm{CO}_{3}\right)_{\text {y }}$ ceramics with controlled composition. J. Eur. Ceram. Soc. 2008, 28, 139-147. [CrossRef]

32. Astala, R.; Stott, M.J. First Principles Investigation of Mineral Component of Bone: CO3 Substitutions in Hydroxyapatite. Chem. Mater. 2005, 17, 4125-4133. [CrossRef]

33. Carrodeguas, R.G.; De Aza, S. $\alpha$-Tricalcium phosphate: Synthesis, properties and biomedical applications. Acta Biomater. 2011, 7, 3536-3546. [CrossRef] [PubMed] 